\title{
Study of meteorological impact on air quality in a humid tropical urban area
}

\author{
C G Hrishikesh* and S M Shiva Nagendra \\ Department of Civil Engineering, Indian Institute of Technology Madras, Chennai 600 036, India. \\ *Corresponding author. e-mail: hcgautam.nitk@gmail.com
}

MS received 13 November 2017; revised 3 September 2018; accepted 14 September 2018; published online 8 May 2019

Urban air quality is highly dynamic and influenced by micrometeorological conditions. In this paper, meteorological impact on criteria air pollutants namely sulphur dioxide $\left(\mathrm{SO}_{2}\right)$, nitrogen dioxide $\left(\mathrm{NO}_{2}\right)$ and particulate matter $\left(\mathrm{PM}_{10}\right)$ were studied using correlation analysis at contrasting locations in the urban environment of Chennai city. Daily average air quality data from five monitoring stations during 2009-2012 were analysed. Out of the five monitoring locations, three locations (Kathivakkam, Thiruvottiyur and Manali) were categorised as industrial locations, General Hospital as a traffic intersection and Taramani as a residential location. The frequency distribution of industrial sites showed higher concentration compared to residential and traffic intersection sites (TS). The increase in annual average concentration of 15-38\%, 4-52\% and 5-58\% was observed for $\mathrm{SO}_{2}, \mathrm{NO}_{2}$ and $\mathrm{PM}_{10}$ over the study period, respectively, attributed to vehicular and industrial emissions. $\mathrm{SO}_{2}$ showed high correlation with humidity $(R=-0.57)$ and cloud cover $(R=0.63)$ during summer. $\mathrm{NO}_{2}$ showed a higher correlation with temperature $(R=0.72)$ during monsoon, and with humidity $(R=0.7)$ and cloud cover $(R=0.75)$ during winter. $\mathrm{PM}_{10}$ showed moderate correlation with temperature $(R=-0.55)$ and wind speed $(R=-0.51)$ during summer. Non-parametric tests and $Q-Q$ plot showed the distribution of $\mathrm{SO}_{2}$ and $\mathrm{NO}_{2}$ as Weibull and lognormal for $\mathrm{PM}_{10}$. The wind rose plots depicted predominant wind direction in the south and south-west directions with most observations having a wind speed of $\geq 5 \mathrm{~m} / \mathrm{s}$. The estimated national ambient air quality index was good for traffic and residential sites. Industrial sites were moderately polluted during the winter season due to high $\mathrm{PM}_{10}$ concentration. No exceedances were observed for daily concentration of $\mathrm{SO}_{2}$ and $\mathrm{NO}_{2}$. Daily average $\mathrm{PM}_{10}$ concentration showed exceedances at industrial locations Kathivakkam, Manali and Thiruvottiyur for 305 (92\%), 84 (68\%) and 164 (53.4\%) days, respectively. At TS (General Hospital) and residential site (RS) (Taramani), lower number of exceedances was observed at $25(13.2 \%)$ days and $11(5.8 \%)$ days, respectively.

Keywords. Urban air quality; correlation analysis; $Q-Q$ plot; Kolmogorov-Smirnov test; wind rose diagram; national air quality index.

\section{Introduction}

Rapid degradation of urban air quality has become a major health concern worldwide in recent decades (Mage et al. 1996; Mayer 1999; Baldasano et al.
2003; Gurjar et al. 2008). Infrastructure development in urban areas including high rise buildings, flyovers and reduced green cover has resulted in

Supplementary material pertaining to this article is available on the Journal of Earth System Science website (http://www. ias.ac.in/Journals/Journal_of_Earth_System_Science). 
poor air circulation within cities. The increase in vehicular population and emissions due to vehicles are accumulating within the lower boundary of the urban atmosphere (Masiol and Harrison 2015). The trend of the past air quality data of many cities indicated that proper land-use planning is a must to achieve better air quality (Frank et al. 2006; Hoek et al. 2008). Therefore, analysis of air quality trends and their associated relation with ambient meteorological conditions will provide useful information to the urban planners, policymakers and other stakeholders. In the present study, the temporal trends of three criteria pollutants $\left(\mathrm{PM}_{10}\right.$, $\mathrm{SO}_{2}$ and $\mathrm{NO}_{2}$ ) and meteorological parameters and their interrelation were studied at urban monitoring locations in the Chennai metropolitan area. A rapid increase in emissions has led to serious health issues, degraded quality of life and increased mortality rate, especially in megacities.

Sulphur dioxide $\left(\mathrm{SO}_{2}\right)$ is produced by the combustion of sulphur containing compounds that are present in most of the fossil fuels (Tecer and Tagil 2013). Short-term exposure of $\mathrm{SO}_{2}$ has been linked to bronchoconstriction and to increased asthma symptoms at higher concentrations (Nadel et al. 1965). $\mathrm{SO}_{2}$ can also react with other compounds to produce fine particulates. Wet and dry depositions contribute as a sink for $\mathrm{SO}_{2}$.

Thermal power plants and automobile exhausts are the major sources for nitrogen dioxide $\left(\mathrm{NO}_{2}\right)$. Inhalation can lead to respiratory tract inflammation and worsening of condition for patients with asthma, emphysema and heart diseases (Monn 2001). $\mathrm{NO}_{2}$ is removed from the atmosphere by conversion into a secondary pollutant, nitrate.

Respirable suspended particulate matter, also denoted as $\mathrm{PM}_{10}$, have aerodynamic diameter less than $10 \mu \mathrm{m}$ and include particles and liquid droplets. It constitutes components like acid salts (nitrate and sulphate), organic chemicals, metals, and soil and dust particles. Exposure to an excess concentration of $\mathrm{PM}_{10}$ causes aggravation of asthma symptoms, irritation of the respiratory tract, and worsening of heart conditions such as ischaemic heart disease and dysrhythmias, leading to premature death due to heart failure and cardiac arrest (Kampa and Castanas 2008). Chennai being a major metropolitan and industrial hub has shared the same fate. Chennai city is the fourth largest city in India with a population of 6.72 million. The city has been described as the 'Detroit of India' due to its large automobile industry, contributing to $30 \%$ of automobiles and $40 \%$ of auto-parts manufactured in India. Chennai city has been classified as a non-attainment area for $\mathrm{PM}_{10}$ due to the number of exceedances over the National Ambient Air Quality Standards (NAAQS) [Central Pollution Control Board (Ministry of Environment and Forests) 2011].

Various studies have been conducted to perceive the effect of meteorological parameters on the ambient concentration of criteria pollutants. Banerjee et al. (2011) analysed the statistical dependency of criteria pollutants, $\mathrm{SO}_{2}, \mathrm{NO}_{2}$ and total suspended particulate matter (TSPM), on different meteorological parameters such as relative humidity $(\mathrm{RH})$, wind speed (WS), precipitation $(P)$ and mean air temperature $(T)$ at Pantnagar, India from May 2008 to April 2009. Both $\mathrm{NO}_{2}$ and TSPM concentrations showed a higher dependency on meteorological parameters as compared to $\mathrm{SO}_{2}$. Partial correlation coefficients revealed that wind speed had the maximum influence on $\mathrm{NO}_{2}$ and $\mathrm{SO}_{2}$, closely followed by weekly mean temperature. However, in the case of TSPM, the individual contribution of ambient temperature was found to be the maximum, followed by relative humidity (Banerjee et al. 2011). Jayamurugan et al. (2013) did a regression analysis for northern Chennai during 2010-2011 and found a negative correlation of $\mathrm{SO}_{2}$ and $\mathrm{NO}_{2}$ with temperature, whereas a significant positive correlation was found in the case of $\mathrm{PM}_{10}$ with temperature due to the absence of scrubbing action during the summer season (Jayamurugan et al. 2013). Chelani et al. (2002) developed a five class air quality index (AQI) to assess the air quality at industrial, commercial and residential locations in five major cities (Mumbai, Delhi, Calcutta, Chennai and Nagpur) in India. They found Delhi to be the most polluted city followed by Calcutta and Mumbai (Chelani et al. 2002). The current study reveals the impact of meteorology on concentration of criteria pollutants and temporal variation of pollutant concentration. The national air quality index (NAQI) for the study area is also analysed. The current study also deals with the determination of the statistical distribution of air pollutant concentration data using quantile-quantile plot $(Q-Q$ plot), a graphical technique used to compare a given data distribution (air pollutant concentration in our case) with a given statistical distribution. The technique is elaborated in the methodology section. Data distribution is very helpful in the calculation of NAAQS exceedance, AQI and forecasting pollutant 

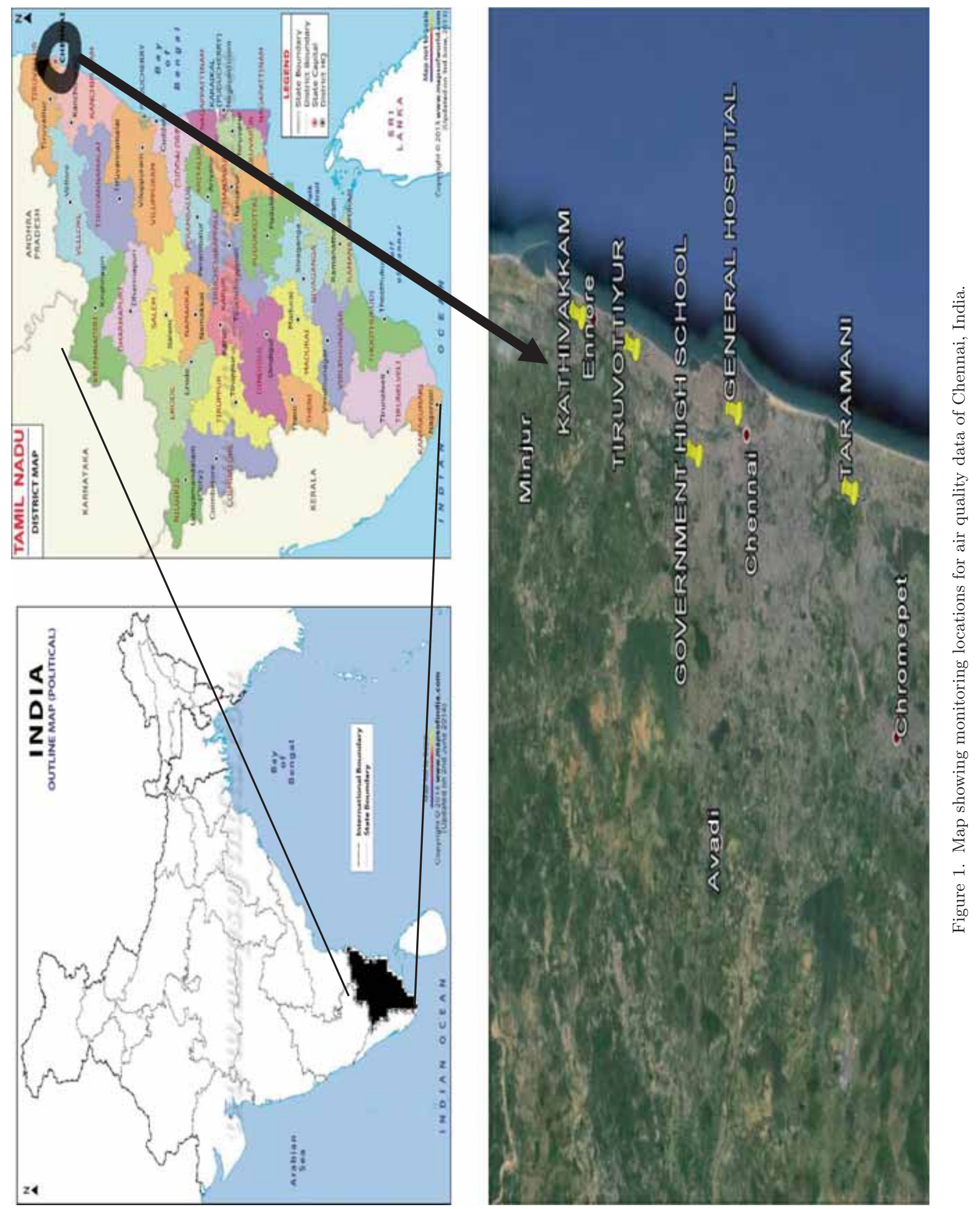
Table 1. Details of monitoring location.

\begin{tabular}{|c|c|c|c|c|}
\hline Location & Type & $\begin{array}{l}\text { Latitude and } \\
\text { Longitude }\end{array}$ & $\begin{array}{l}\text { Pollutants } \\
\text { monitored }\end{array}$ & Major sources \\
\hline $\begin{array}{l}\text { Kathivakkam } \\
\text { (IS-1) }\end{array}$ & Industrial & $13.21^{\circ} \mathrm{N}, 80.32^{\circ} \mathrm{E}$ & $\mathrm{PM}_{10}, \mathrm{SO}_{2}, \mathrm{NO}_{2}$ & $\begin{array}{l}\text { Ennore power plant, Ennore } \\
\text { port }\end{array}$ \\
\hline $\begin{array}{l}\text { Thiruvottiyur } \\
\text { (IS-2) }\end{array}$ & Industrial & $13.16^{\circ} \mathrm{N}, 80.30^{\circ} \mathrm{E}$ & $\mathrm{PM}_{10}, \mathrm{SO}_{2}, \mathrm{NO}_{2}$ & $\begin{array}{l}\text { Royal Enfield Motors, } \\
\text { Greaves Cotton Ltd, Shri } \\
\text { Ram Fibers Ltd., Ashok } \\
\text { Leyland, Ennore foundries, } \\
\text { Ennore thermal power } \\
\text { station }\end{array}$ \\
\hline Manali (IS-3) & Industrial & $13.16^{\circ} \mathrm{N}, 80.25^{\circ} \mathrm{E}$ & $\mathrm{PM}_{10}, \mathrm{SO}_{2}, \mathrm{NO}_{2}$ & $\begin{array}{l}\text { CPCL (Chennai Petroleum } \\
\text { Corporation limited), } \\
\text { Madras Fertilizers Limited } \\
\text { (MFL), Manali } \\
\text { Petro-Chemical Ltd } \\
\text { (MPCL) }\end{array}$ \\
\hline $\begin{array}{l}\text { General hospital } \\
\text { (TS) }\end{array}$ & Traffic intersection & $13.08^{\circ} \mathrm{N}, 80.27^{\circ} \mathrm{E}$ & $\mathrm{PM}_{10}, \mathrm{SO}_{2}, \mathrm{NO}_{2}$ & $\begin{array}{l}\text { Chennai central railway } \\
\text { station, Park town railway } \\
\text { station, MRTS (Mass Rapid } \\
\text { Transit system), daily } \\
\text { traffic }\end{array}$ \\
\hline Taramani (RS) & Residential & $12.98^{\circ} \mathrm{N}, 80.24^{\circ} \mathrm{E}$ & $\mathrm{PM}_{10}, \mathrm{SO}_{2}, \mathrm{NO}_{2}$ & $\begin{array}{l}\text { IT Park, Old mahabalipuram } \\
\text { road (OMR) }\end{array}$ \\
\hline
\end{tabular}

concentration (Jakeman 1986; Taylor et al. 1986; Jakeman et al. 1988). Data distribution identification helps us with the removal of noise caused by human error or erroneous instrumentation during the monitoring of pollutant concentration (Holland and Fitz-simons 1981; Berger et al. 1982; Gokhale and Khare 2007).

\section{Materials and methods}

\subsection{Description of study area}

\subsubsection{Chennai city}

Chennai city is located on the south-eastern coast of peninsular India bound between $12^{\circ} 50^{\prime} 49^{\prime \prime}$ $13^{\circ} 17^{\prime} 24^{\prime \prime}$ latitude and $79^{\circ} 59^{\prime} 53^{\prime \prime}-80^{\circ} 20^{\prime} 12^{\prime \prime}$ longitude. It has a flat coastal terrain with an average elevation of $6.7 \mathrm{~m}$ (Krishnamurthy and Desouza 2015). It stretches along a length of $25.6 \mathrm{~km}$ with an area of $176 \mathrm{~km}^{2}$.

The weather in Chennai is sub-tropical (hot and humid) with four seasons, i.e., winter, summer, pre-monsoon and monsoon. Winter season occurs between January and February, summer from March to May, pre-monsoon or south-west monsoon from June to September and postmonsoon or north-east monsoon from October to
December with an average temperature of $25.7^{\circ} \mathrm{C}$, $30.6^{\circ} \mathrm{C}, 29.8^{\circ} \mathrm{C}$ and $26.8^{\circ} \mathrm{C}$, respectively. Season of post-monsoon or north-east monsoon accounts for $60 \%$ of the annual rainfall.

The daily average concentration of the three criteria pollutants, $\mathrm{SO}_{2}, \mathrm{NO}_{2}$ and $\mathrm{PM}_{10}$, were collected over the years 2009-2012 from Tamil Nadu Pollution Control Board (TNPCB). TNPCB monitors the air quality twice a week under the National Ambient Air Quality Monitoring Programme (NAAMP) at five monitoring locations in the Chennai city as shown in figure 1. Among the five monitoring locations, three locations (Kathivakkam, Thiruvottiyur and Manali) are designated as industrial locations IS-1 to IS-3, General Hospital monitoring site is designated as traffic intersection site (TS) and Taramani as the residential site $(\mathrm{RS})$ as shown in table 1.

\subsection{Data collection}

Air quality was monitored by the TNPCB at selected locations, as described in section 2.1. High-volume sampler (Envirotech India, Model AQM $460 \mathrm{NL}$ ) was used for collection of pollutant data. $\mathrm{PM}_{10}$ data were collected through gravimetric separation using glass fibre filter paper. An integrated gas sampling assembly with $35 \mathrm{ml}$ 
impingers for the collection of $\mathrm{SO}_{2}$ and $\mathrm{NO}_{2}$ was connected to the high-value sampler for analysis of gaseous pollutants. Colorimetric Jacobs and Hochheiser modified method was used for the measurement of $\mathrm{NO}_{2}$ concentration. $\mathrm{NO}_{2}$ was collected in the impinger by flowing air through a solution of sodium hydroxide and sodium arsenite. The concentration of the nitrite ion $\left(\mathrm{NO}_{2}\right)$ produced during sampling was determined colorimetrically by reaction of the nitrite ion with phosphoric acid, sulphanilamide and $N$-(1-naphthyl)ethylenediamine di-hydrochloride (NEDA) and measuring the absorbance of the azo-dye at 540 nm. Modified West and Gaeke method was used for the measurement of $\mathrm{SO}_{2}$ concentration (Kamyotra and Basu 2011). Sulphur dioxide from the air is absorbed in a solution of potassium tetrachloromercurate (TCM), which forms a dichlorosulphitomercurate complex, which resists oxidation in the air. The complex is stable to strong oxidants such as ozone and oxides of nitrogen and therefore, the absorber solution can be stored for some time prior to analysis. The complex is made to react with para-rosaniline and formaldehyde to form the intensely coloured pararosaniline methylsulphonic acid. The absorbance of the solution is measured by means of a spectrophotometer. Meteorological data for the study period were collected from the Weather Underground website http://www. wunderground.com (Weather Underground 2018). Weather Underground collects the daily average meteorological data from the weather monitoring station at the Chennai international airport. Uncertainty in sampling or analysis can occur due to various reasons. It could be an instrumental error like flow measurement error in high-volume sampler or human error during sampling and data handling. TNPCB takes care of these uncertainties by validating data through a stringent quality assurance process before uploading. We have further cross-verified the data for outliers using quartile test. No outliers were found during the test.

\subsection{Statistical techniques}

\subsubsection{Exploratory statistical analysis}

Correlation analysis determines the strength of the statistical relationship, i.e., dependence among the variables (pollutant concentration in the current case). The high positive correlation indicates a strong relationship between the parameters, and high (or low) values of one parameter occur in conjunction with the high (or low) values of the other parameter. If the correlation is negative and large, the relationship is strong but inverse. In the current study, Pearson's product moment correlation (PMCC) was used.

PMCC is calculated based on individual observations and studies based on the case of linear dependency. It was first proposed by Francis Galton (Stigler 1989) and formally developed by Karl Pearson. It is defined as the covariance of two datasets divided by the product of standard deviations as shown in

$$
R_{\mathrm{p}}=\frac{\sum_{i=1}^{n}\left(x_{i}-\bar{x}\right)\left(y_{i}-\bar{y}\right)}{\left[\sum_{i=1}^{n}\left(x_{i}-\bar{x}\right)^{2} \sum_{i=1}^{n}\left(y_{i}-\bar{y}\right)^{2}\right]^{1 / 2}}
$$

Box plots depict the monthly variation and range of concentration of criteria pollutants through their quartiles. The median value for the month is shown by the red horizontal line, whereas the first and third quartiles are shown by the lower and upper boundaries of the box and the lowest and highest concentrations are demarcated by the lower and upper ends of the whiskers extending from the box.

\subsection{Statistical distribution identification}

The distribution of the probability of occurrence of a given value of pollutant concentration is termed as a statistical distribution or probability distribution function. Several statistical tests have been developed over the years for the identification of distribution of any set of data. In the current study, two hypothesis tests, i.e., Anderson-Darling test and Kolmogorov-Smirnov test, and a graphical method, $Q-Q$ method, have been used for distribution identification and verification. The tests were applied on the pollutant concentration data for probability distributions, as shown in table 2 .

The hypothesis tests are used to check whether a given data sample comes from a population with a specified probability distribution (Jakeman et al. 1988; Chelani et al. 2002; Jayamurugan et al. 2013). The cumulative distribution function (cdf) of the data is compared with the empirical cdf of a theoretical statistical distribution. The maximum absolute distance between the two distributions is used as a test statistic. The Anderson-Darling test is much preferred compared to the KolmogorovSmirnov test as it gives more weightage to the tails of the distribution and is better for outlier values, whereas Kolmogorov-Smirnov test is more sensitive to the central values compared to the tails. 
Table 2. Statistical details for different Probability distribution.

\begin{tabular}{lll}
\hline Distribution & \multicolumn{1}{c}{ Equation } & \multicolumn{1}{c}{ Range } \\
\hline Normal & $\frac{1}{\sqrt{2 \pi \sigma^{2}}} e^{-\frac{(x-\mu)^{2}}{2 \sigma^{2}}}$ & $0 \leq x \leq \infty$ \\
Lognormal & $\frac{1}{x \sigma \sqrt{2 \pi}} e^{-\frac{(\ln x-\mu)^{2}}{2 \sigma^{2}}}$ & $0 \leq x \leq \infty$ \\
Exponential & $\lambda e^{-\lambda x}$ & $0 \leq x \leq \infty$ \\
Gamma & $\frac{1}{\Gamma(k) \theta^{k}} x^{k-1} e^{-\frac{x}{\theta}}$ & $-\infty \leq x \leq \infty$ \\
Weibull & $f(x)=\left\{\begin{array}{l}\frac{k}{\lambda}\left(\frac{x}{\lambda}\right)^{k-1} \\
0\end{array}\right.$ & $0 \leq x \leq \infty ;$ \\
Generalized & $\frac{1}{\sigma}(1+\varepsilon z)^{-\left(\frac{1}{\varepsilon}+1\right)}$ & $-\infty \leq x \leq \infty$ \\
Pareto & $\mathrm{where} z=\frac{x-\mu}{\sigma}$ & $-\infty \leq x \leq \infty$ \\
Logistic & $\frac{e^{-\frac{x-\mu}{s}}}{\left(1+e^{-\frac{x-\mu}{s}}\right)^{2}}$ & $-\infty \leq x \leq \infty$ \\
Loglogistic & $\frac{(\beta / \alpha)(x / \alpha)^{\beta-1}}{\left(1+(x / \alpha)^{\beta}\right)^{2}}$ & \\
\hline
\end{tabular}

\subsection{National air quality index}

AQI is a representation of air quality status in terms of health effects on the residents of a locality (Shooter and Brimblecombe 2005; Plaia and Ruggieri 2010; Kanchan et al. 2015). It is represented as a numerical or linguistic value based classification scheme. Several air quality indices have been developed over the years based on the number of pollutants, aggregation methods or health effects being considered (Holland and Fitz-simons 1981).

NAQI derived from the US EPA's AQI is based on linear interpolation of air pollutant concentration to air quality classes based on effects of specific pollutants on health.

$$
I_{\mathrm{p}}=\frac{\left(I_{\mathrm{HI}}-I_{\mathrm{LO}}\right)}{\mathrm{BP}_{\mathrm{HI}}-\mathrm{BP}_{\mathrm{LO}}}\left(C_{\mathrm{P}}-\mathrm{BP}_{\mathrm{LO}}\right)+I_{\mathrm{LO}},
$$

where $I_{\mathrm{P}}$ is the index for pollutant $\mathrm{P}, C_{\mathrm{P}}$ is the rounded concentration of pollutant $\mathrm{P}, \mathrm{BP}_{\mathrm{HI}}$ is the break point that is greater than or equal to $C_{\mathrm{P}}$, $\mathrm{BP}_{\mathrm{LO}}$ is the Breakpoint that is less than or equal to $C_{\mathrm{P}}, I_{\mathrm{HI}}$ is the AQI value corresponding to $\mathrm{BP}_{\mathrm{HI}}$ and $I_{\mathrm{LO}}$ is the AQI value corresponding to $\mathrm{BP}_{\mathrm{LO}}$.

\section{Results and discussion}

\subsection{Air quality data}

Tables S1-S3 in the supplementary material show the seasonal mean, standard deviation and 24-hr average minimum and maximum concentrations of $\mathrm{SO}_{2}, \mathrm{NO}_{2}$ and $\mathrm{PM}_{10}$ at the monitoring locations. No exceedances above the NAAQS level were observed for $\mathrm{NO}_{2}$ concentration during the study duration. Predominantly higher concentration was observed at Manali (IS-3) and Thiruvottiyur (IS-2) as compared to General Hospital (TS) and Taramani (RS). The highest $\mathrm{SO}_{2}$ concentration of $25.7 \mu \mathrm{g} / \mathrm{m}^{3}$ was observed at Manali (IS-3) in winter and the lowest concentration of $2 \mu \mathrm{g} / \mathrm{m}^{3}$ at General Hospital (TS) during monsoon. Table S2 shows the highest and lowest 24-hr average $\mathrm{NO}_{2}$ concentration of $33.1 \mu \mathrm{g} / \mathrm{m}^{3}$ and $3.2 \mu \mathrm{g} / \mathrm{m}^{3}$ at Thiruvottiyur (IS-2) during the winter and at Taramani during the monsoon season and a maximum and minimum seasonal average of $23.8 \mu \mathrm{g} / \mathrm{m}^{3}$ and $6.3 \mu \mathrm{g} / \mathrm{m}^{3}$ at Manali during the winter and at Taramani during the monsoon, respectively.

Table S3 depicts the seasonal maximum, minimum, average and standard deviation of $\mathrm{PM}_{10}$ concentration. Maximum and minimum concentration was observed to be 200 and $5.5 \mu \mathrm{g} / \mathrm{m}^{3}$ at Manali during the winter and General Hospital during the monsoon, respectively. Similarly, the seasonal average maximum and minimum of $141 \mu \mathrm{g} / \mathrm{m}^{3}$ during the winter at Manali and $12.5 \mu \mathrm{g} / \mathrm{m}^{3}$ during the pre-monsoon at General Hospital, respectively.

Tables S7 and S8 show the exceedances of NAAQS for $\mathrm{PM}_{10}$ concentration as number as well as percentage of total observations. No exceedances were observed for $\mathrm{NO}_{2}$ and $\mathrm{SO}_{2}$ concentration for any of the locations. The highest number of exceedances was observed at Manali and Kathivakkam with $100 \%$ exceedance during the winter season for both the locations. The lowest number of exceedances was observed at Taramani with no exceedance during the summer, pre-monsoon and monsoon seasons.

\subsection{Monthly and seasonal variation}

Data frequency distribution of seasonal average and a monthly average of $\mathrm{SO}_{2}, \mathrm{NO}_{2}$ and $\mathrm{PM}_{10}$ during the study period is shown in line plots in figure 2. Monthly values were calculated from the daily average concentration monitored during the months. Seasonal average was calculated for the seasons, i.e., winter (January-March), summer (April-July), pre-monsoon (August-October) and monsoon (November and December).

No exceedances were observed for monthly and seasonal average concentration of $\mathrm{SO}_{2}$ and $\mathrm{NO}_{2}$. 

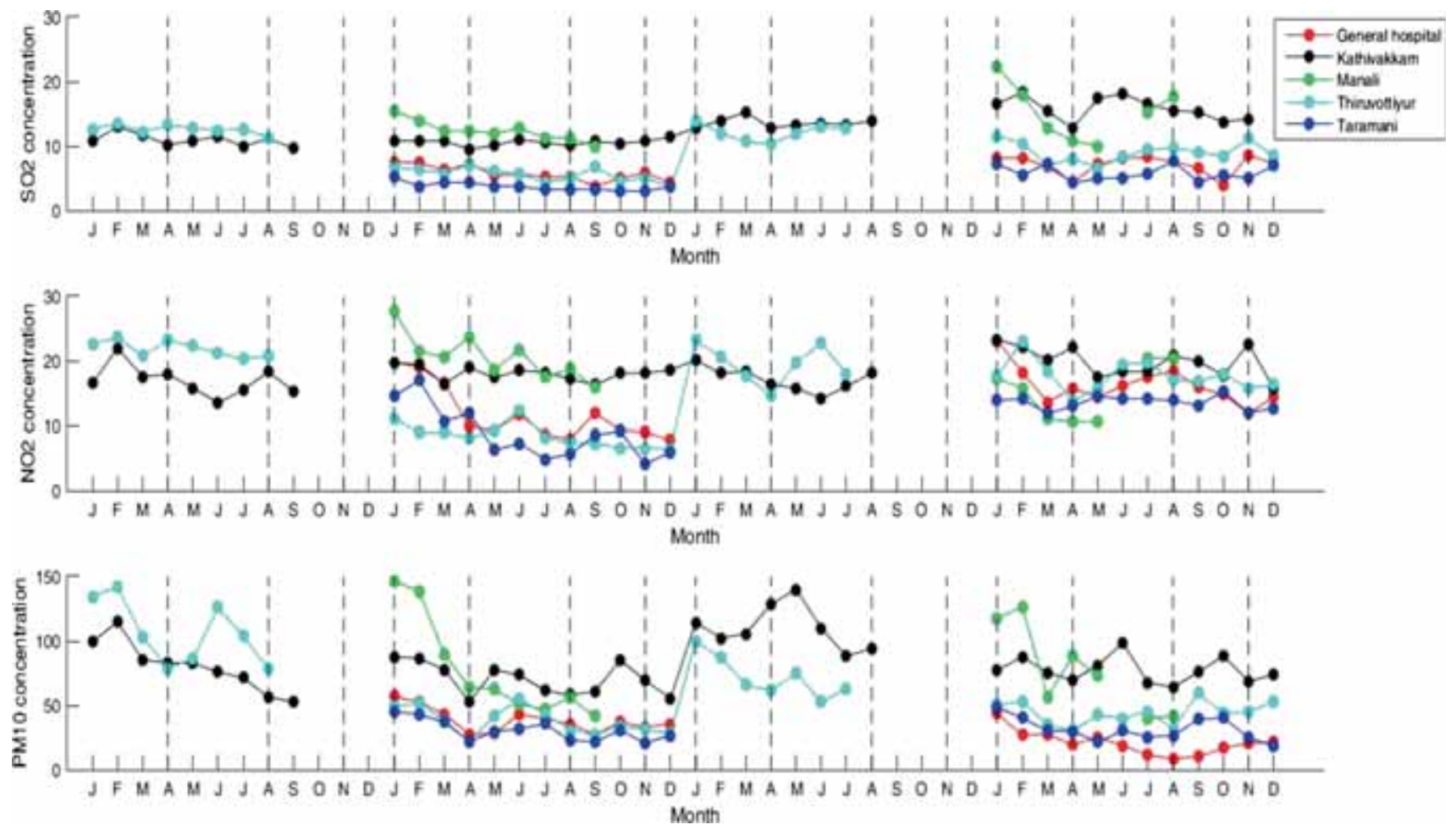

Figure 2. Monthly average pollutant concentration for monitoring locations in the study area, where $\mathrm{J}=\mathrm{January}$, $\mathrm{F}=$ February, $\mathrm{M}=$ March, $\mathrm{A}=$ April, $\mathrm{J}=$ June, $\mathrm{J}=$ July, $\mathrm{A}=$ August, $\mathrm{S}=$ September, O = October, $\mathrm{N}=\mathrm{November}$ and $\mathrm{D}=$ December. All the months were indicated in sequence for four consecutive years (2009-2012).

The seasonal and monthly variation for $\mathrm{SO}_{2}$ concentration was not very prominent but an increase in the concentration has been observed in the winter season as shown in figure 2. A higher concentration during the winter is attributed to stable atmospheric conditions caused by lower mixing height and lower wind velocity (Zvyagintev et al. 2014). Stable atmospheric condition restricts vertical mixing of air mass and dispersion of pollutant leading to pollutant accumulation and higher concentration. An increase in annual average concentration at $15,55,38$ and $23 \%$, respectively, for Manali, Taramani, Kathivakkam and General Hospital and a decrease of $29 \%$ were observed at Thiruvottiyur during the study period, respectively. A distinct difference has been observed between the $\mathrm{SO}_{2}$ concentration at the residential or traffic site and the industrial sites with Kathivakkam and Thiruvottiyur having a higher concentration among the monitoring sites, whereas Taramani and General Hospital having a lower concentration. These differences can be attributed to the industrial emission sources like thermal power station (Ennore thermal power station), automobile industries and other medium-scale industries.
The monthly average of $\mathrm{NO}_{2}$ concentrations was well below the NAAQS as shown in figure 2. Winter months had the highest concentration, whereas a decrease in concentration during the summer was attributed to high temperature and favourable atmospheric air mass exchange. Atmospheric air mass exchange reduces the concentration of pollutant through vertical wind movement below the planetary boundary layer. Monsoon season also shows a decrease in concentration because of dissolution and natural scrubbing caused by the rainwater. The annual average $\mathrm{NO}_{2}$ concentration increased by 52,4 and $37 \%$ over the study period in the case of Taramani, Kathivakkam and General Hospital, respectively. The increase in $\mathrm{NO}_{2}$ concentration can be attributed to increase in the number of vehicles and vehicle travelled over the years (Hargreaves et al. 2000; Bell et al. 2013; Huang et al. 2013) as well as poor inspection and vehicle maintenance systems in the study area. The rapid increase in vehicle numbers (especially diesel vehicles) is attributed to population growth and buying trend of the public in urban areas specifically metropolitan cities like Chennai. In the case of government high school and Thiruvottiyur, the annual 
average concentration decreased by 27 and $20 \%$, respectively.

Monthly variation of $\mathrm{PM}_{10}$ is also shown in figure 2. Exceedances were observed for Manali, Kathivakkam and Thiruvottiyur (all industrial areas) during the winter season. The higher concentration of $\mathrm{PM}_{10}$ was observed in the winter season for all the locations with summer and monsoon showing a decreasing trend with lower concentration. $\mathrm{PM}_{10}$ concentration was considerably low for Taramani. Among the industrial sites, the highest concentration has been observed at Manali and Thiruvottiyur. In 2009, $\mathrm{PM}_{10}$ concentration has violated the NAAQS in Kathivakkam
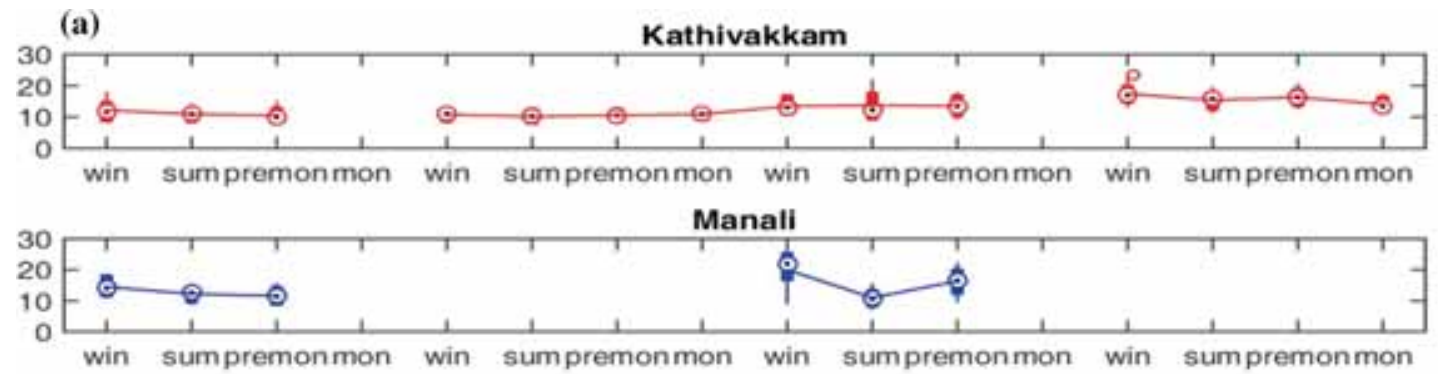

General hospital

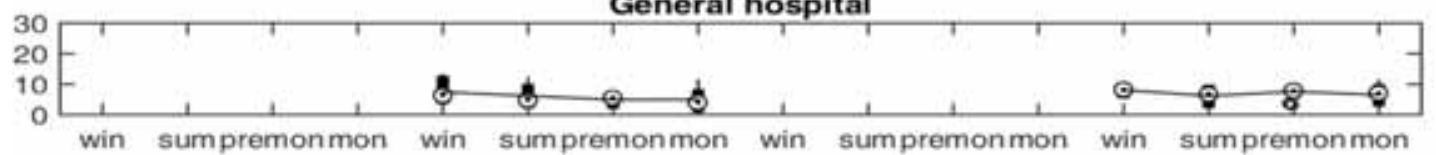

Taramani

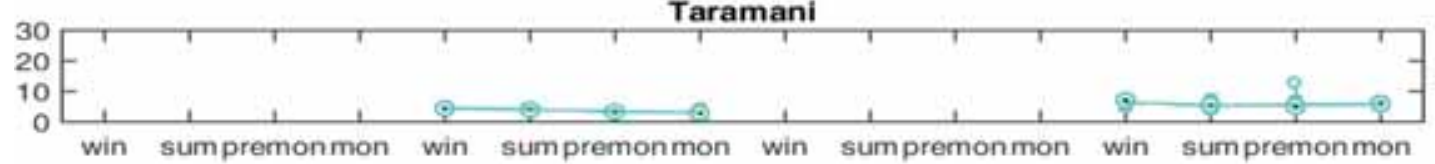

Thiruvottiyur

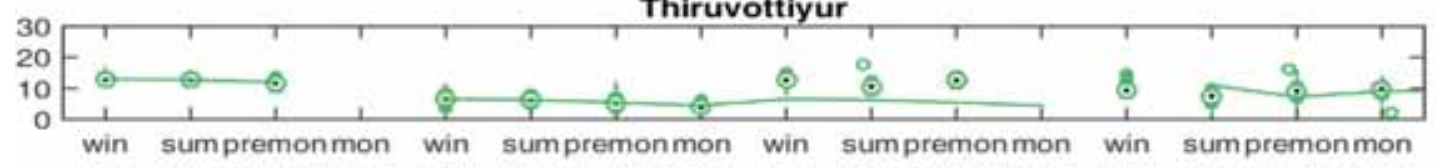

(b)

Kathivakkam
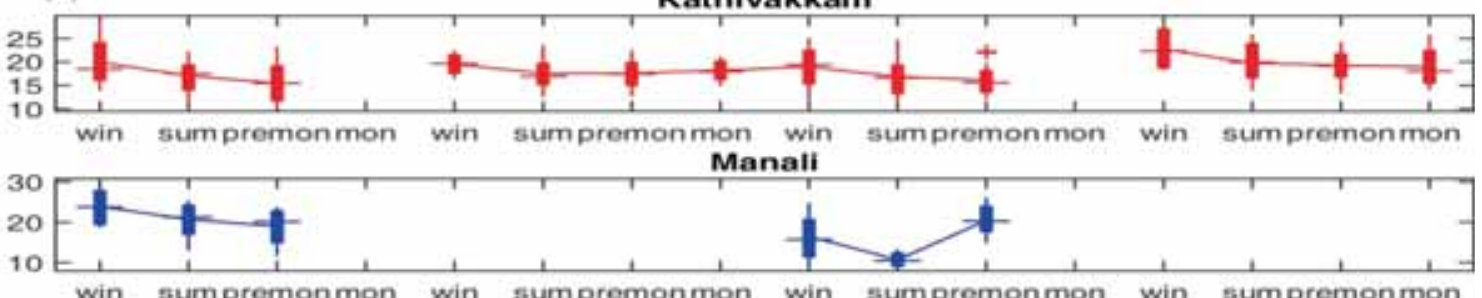

win sumpremonmon win sumpremonmon win sumpremonmon win sumpremonmon

General hospital

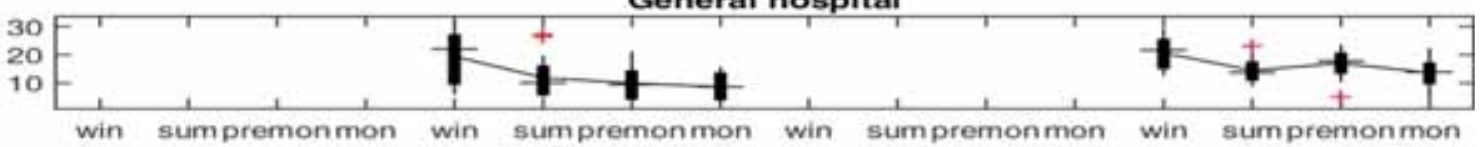

Taramani

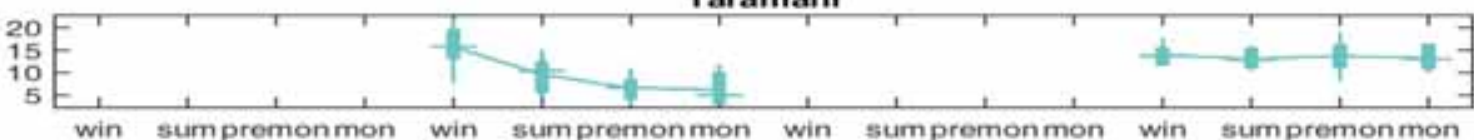

Thiruvottiyur

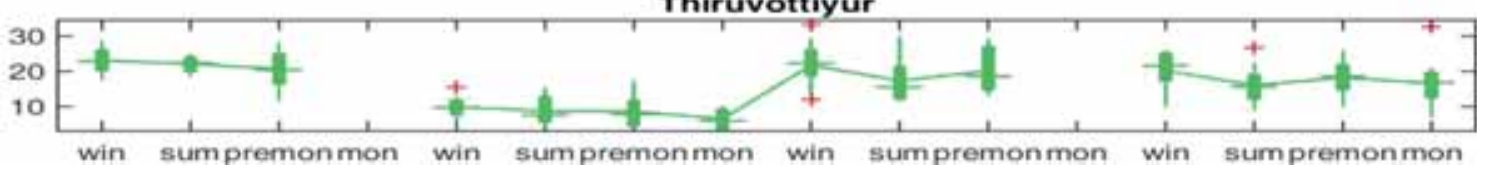

Figure 3. Boxplots of seasonal variation of pollutant concentration for five monitoring location from 2009 to 2012 for (a) $\mathrm{SO}_{2}$, (b) $\mathrm{NO}_{2}$ and (c) $\mathrm{PM}_{10}$. Trend line of monthly average concentration is also represented. 
(c)

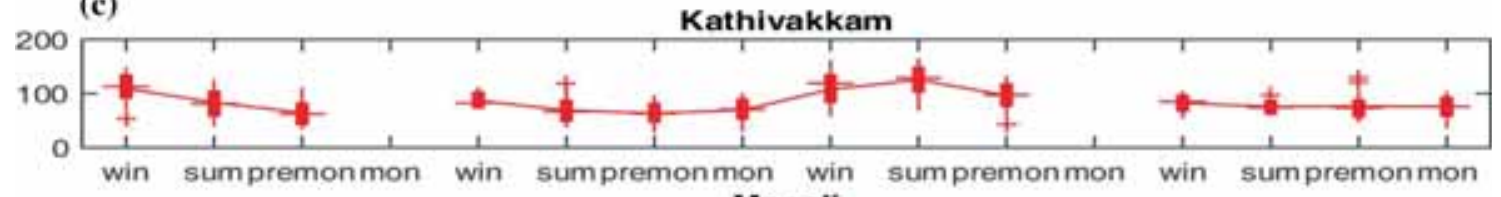
Manali

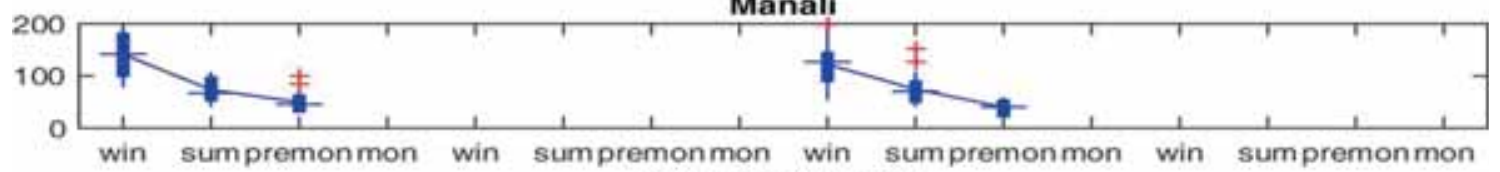

General hospital

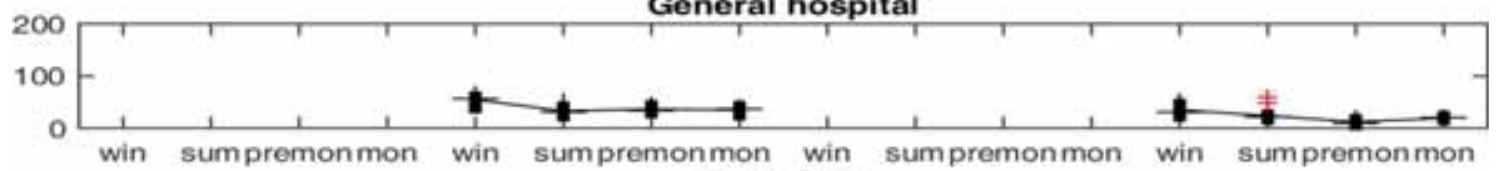

Taramani

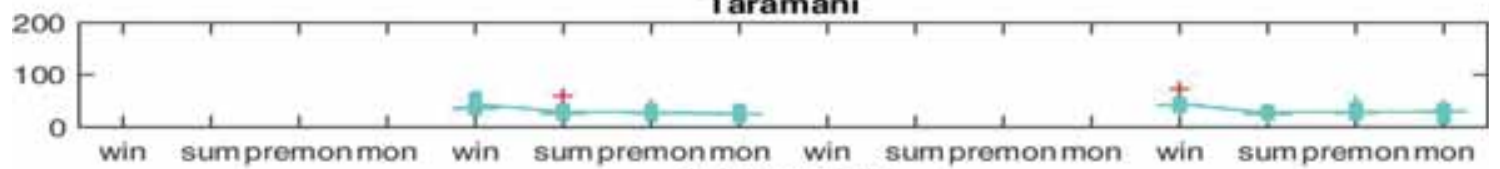

Thiruvottiyur

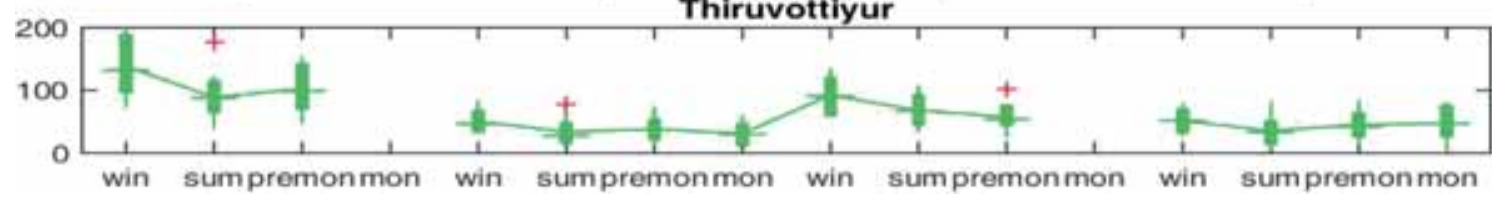

Figure 3. (Continued.)

and Thiruvottiyur monitoring sites for 17 and 32 days, respectively. Similarly, $\mathrm{PM}_{10}$ concentration exceeded the NAAQS at Kathivakkam and Manali in 2010 for 5 and 12 days and at Kathivakkam and Thiruvottiyur in 2011 for 45 and 10 days, respectively. A number of exceedances observed for $\mathrm{PM}_{10}$ in the year 2012 were 9 and 16 days, respectively. There is an increase in the annual average concentration of $\mathrm{PM}_{10}$ by $5,28,45$ and $58 \%$ in the case of Manali, Kathivakkam, General Hospital and Thiruvottiyur and a decrease in the concentration by $2 \%$ in the case of Taramani, respectively, were observed.

Figure 3 shows the Box-Whisker plots for monthly average concentration of three criteria pollutants: (a) $\mathrm{SO}_{2}$, (b) $\mathrm{NO}_{2}$ and (c) $\mathrm{PM}_{10}$. The plots have been divided into five subplots with each subplot showing the seasonal trend of pollutant concentration for one of the monitoring locations in Chennai city. The edges of the box represent the upper quartile of the dataset with Whisker edges showing the max and min values. A trend line has also been added to the plot to demarcate the seasonal average trend. In figure 3(a), the first subplot i.e., the boxplot for industrial site at Kathivakkam monthly variation was not very significant for the years 2009

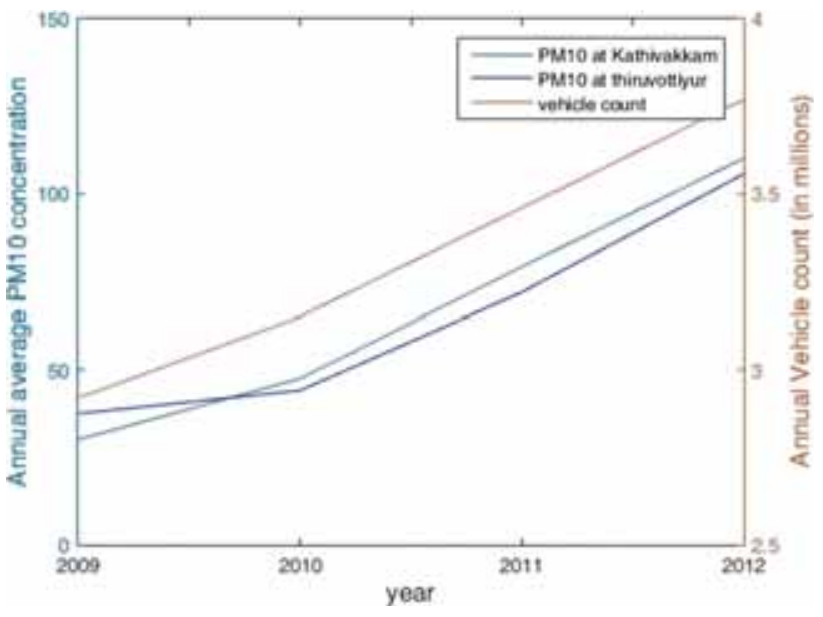

Figure 4. Plot showing an increase in annual concentration of $\mathrm{PM}_{10}$ at two industrial locations (Kathivakkam and Thiruvottiyur) with increase in vehicle count of Chennai city.

and 2010, but during 2011 and 2012 an increasing trend is observed during the winter and a decline in the concentration during the summer months. In the case of Manali industrial area, data available only for the years of 2009 and 2011 showed a trend of higher concentration during the winter season and decline during the summer months. In the plot for TS General Hospital, winter months 
(a)
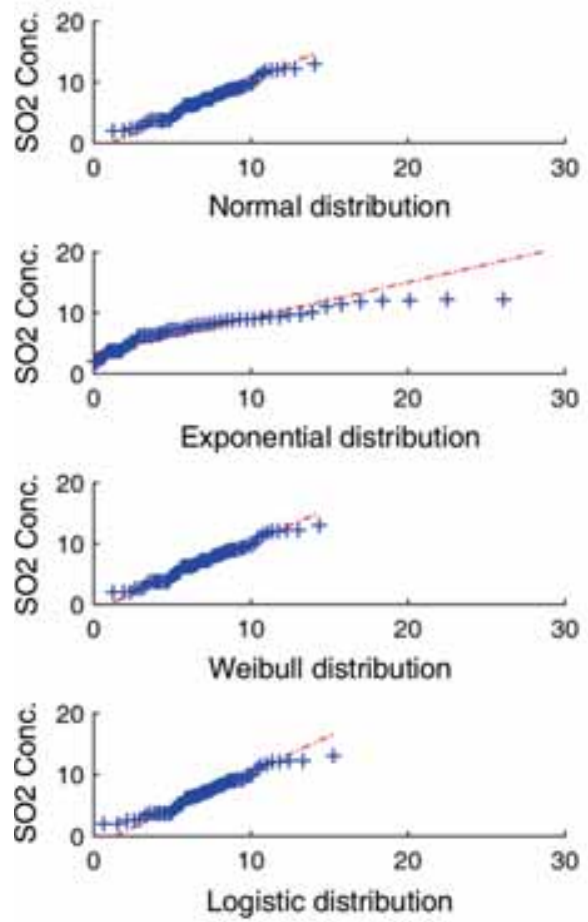

(b)
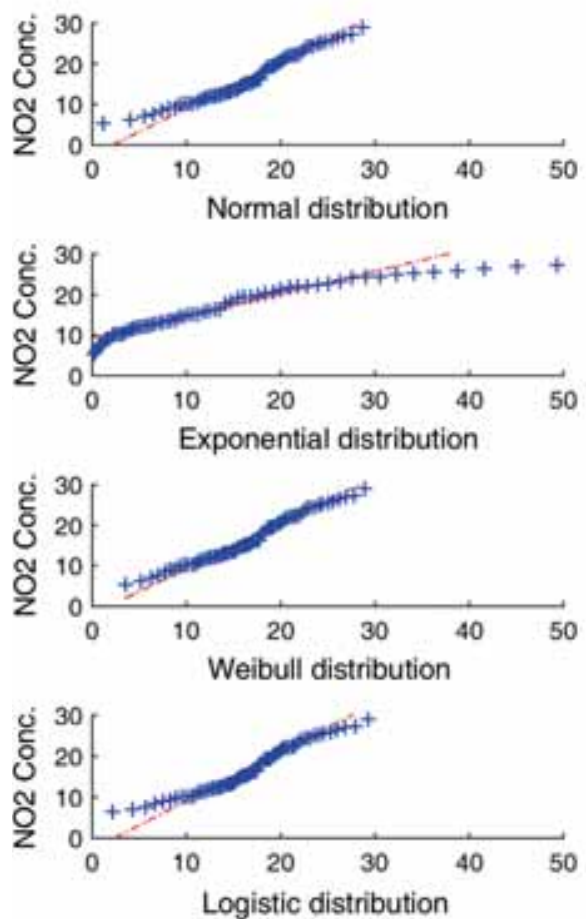
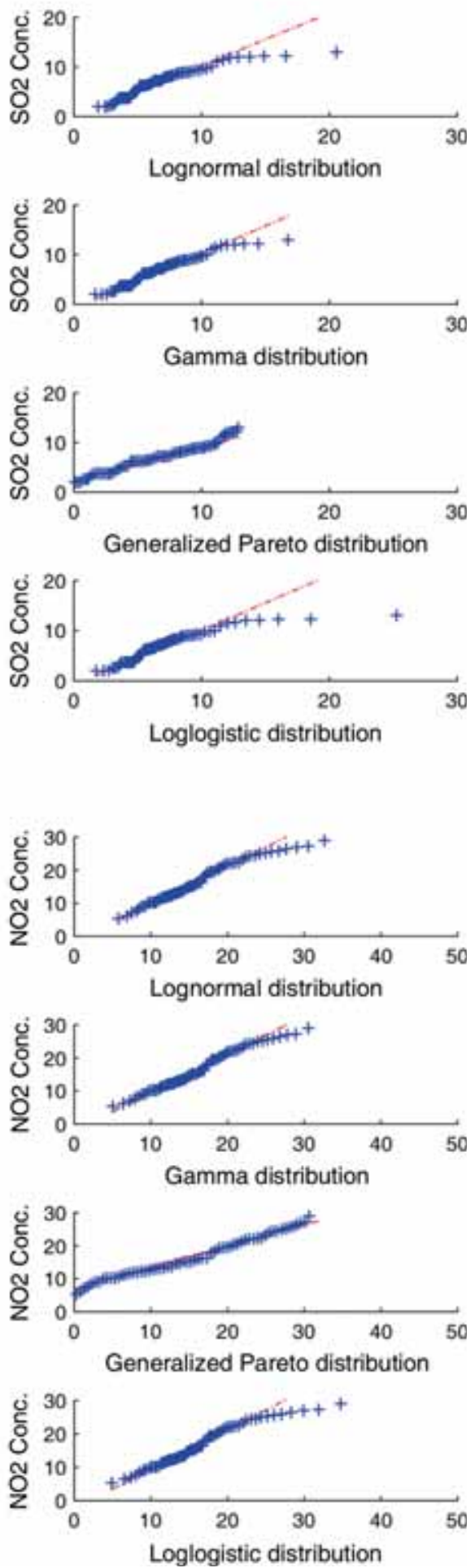

Figure 5. Quantile-Quantile plots $(Q-Q$ plots) of air quality data from General Hospital (TS) monitoring site used for determination of statistical distribution in the case of daily average concentration of (a) $\mathrm{SO}_{2}$, (b) $\mathrm{NO}_{2}$ and (c) $\mathrm{PM}_{10}$.

of January-March showed a comparatively higher trend. A significant variation was not visible in the monthly time series of $\mathrm{SO}_{2}$ concentration for the monitoring stations Taramani and Thiruvottiyur as shown in the fourth and fifth subplots.
When comparing all the locations, the highest concentration was observed at Manali and least at Taramani. A similar trend was observed for $\mathrm{NO}_{2}$ concentration as shown in figure $3(\mathrm{~b})$ with the winter months of January and February having 

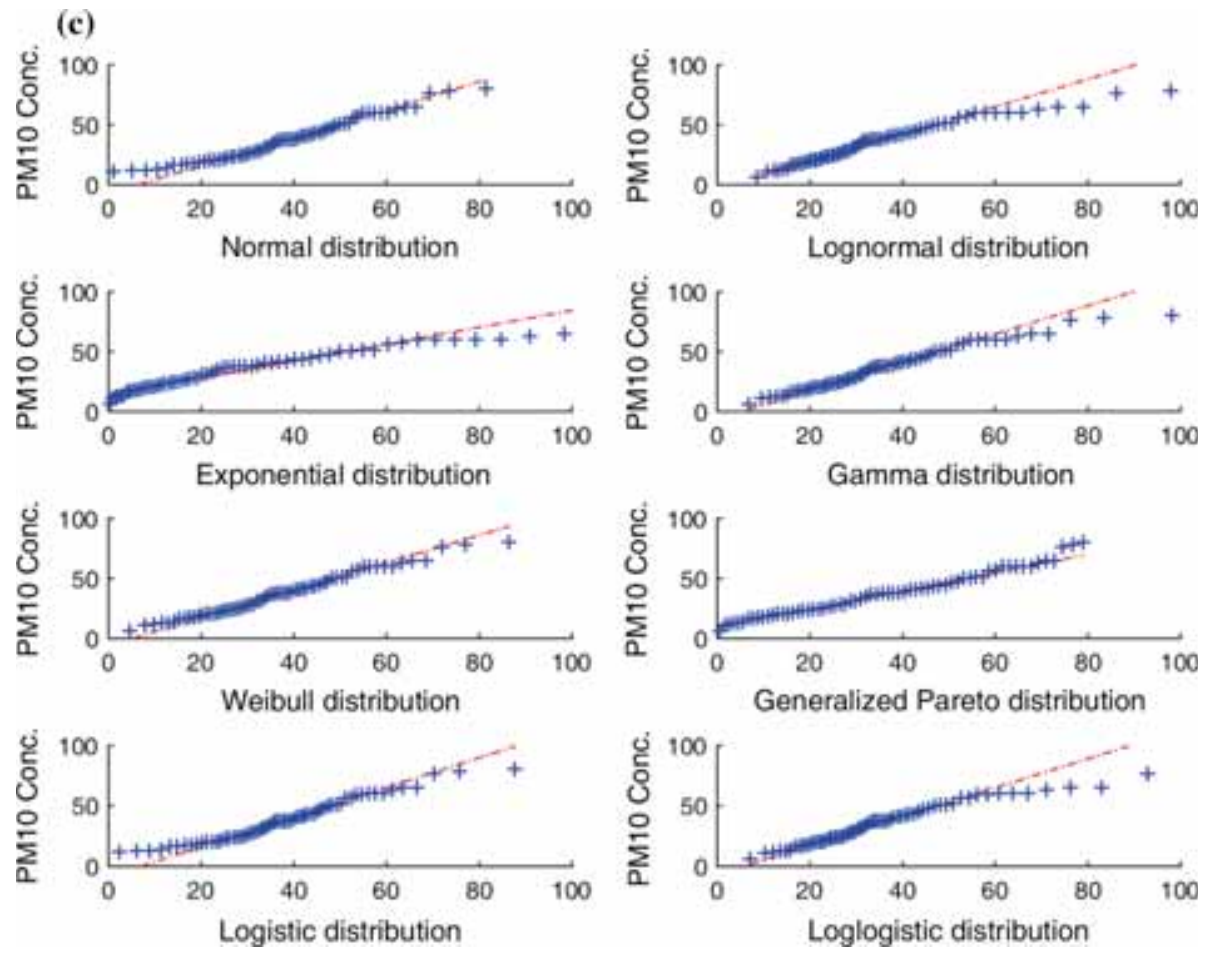

Figure 5. (Continued.)

a higher value for all the five monitoring locations over the years. No exceedance over the NAAQS was observed for any of the observations. A dip in the concentration values was observed in the summer season. The lowest concentrations were observed at Taramani, whereas the highest concentration in the case of General Hospital and Manali. The General Hospital location is very close to traffic intersection which has proximity to vehicular sources. Manali industrial area site has proximity to industrial sources due to heavy industries like petrochemical industries. The trends of seasonal concentration are shown in figure 3(c) with rows of plots representing different monitoring locations and columns representing different years. No exceedances over the NAAQS were observed for the plot that represents TS of General Hospital and subplot that represents the RS of Taramani. A higher monthly average $\mathrm{PM}_{10}$ concentration was observed during the winter season for all the years at most locations. The higher concentration and the increasing trend were observed in the case of industrial sites at Manali having the highest concentration. Figure 4 shows the annual variation of $\mathrm{PM}_{10}$ concentration with increasing number of vehicles in Chennai city. $\mathrm{PM}_{10}$ concentrations at two industrial locations have been used to compare the increasing trends. As shown in figure 4, there is an increase in $\mathrm{PM}_{10}$ concentration (in $\mu \mathrm{g} / \mathrm{m}^{3}$ ) and vehicle number (in millions) over the study duration. The increase in traffic density (vehicular number) is a source of contribution to increase of pollutant concentration, especially $\mathrm{PM}_{10}$, but as the paper is about the effect of meteorology on air quality, the detailed discussion is out of scope.

Chennai data have also been compared with Mumbai city. The daily average concentration of $\mathrm{PM}_{10}, \mathrm{SO}_{2}$ and $\mathrm{NO}_{2}$ was downloaded from data.gov.in website of Government of India (Govt. of India 2018) and the monthly average concentration of each of the pollutant was calculated as shown in tables S3-S6 in the supporting material. Air quality data were measured by Maharashtra Pollution Control Board (MPCB) under the NAAMP programme at two locations Worli (RS) and Parel (industrial site) - for the duration of 2009-2012. Mumbai city was chosen because of its coastal meteorology and being one of the metropolitan cities in India. It has similar conditions in terms of industries and vehicular sources. No exceedances in the monthly values were observed in the case of $\mathrm{SO}_{2}$ and $\mathrm{NO}_{2}$ concentrations, which is quite similar to our observations in the case of Chennai city. Exceedances were 


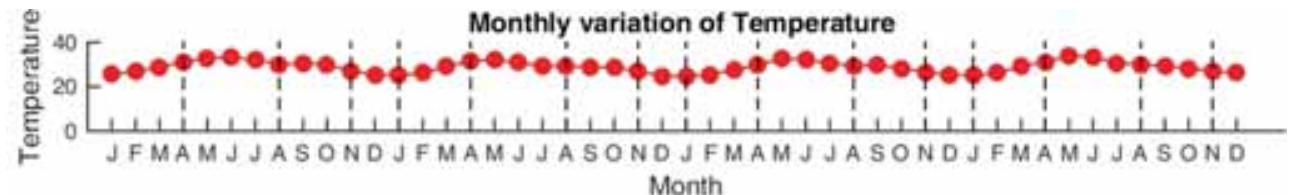

Monthly variation of Humidity

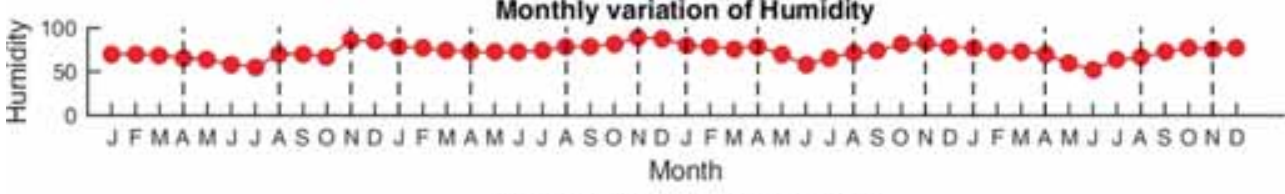

Monthly variation of Visibility
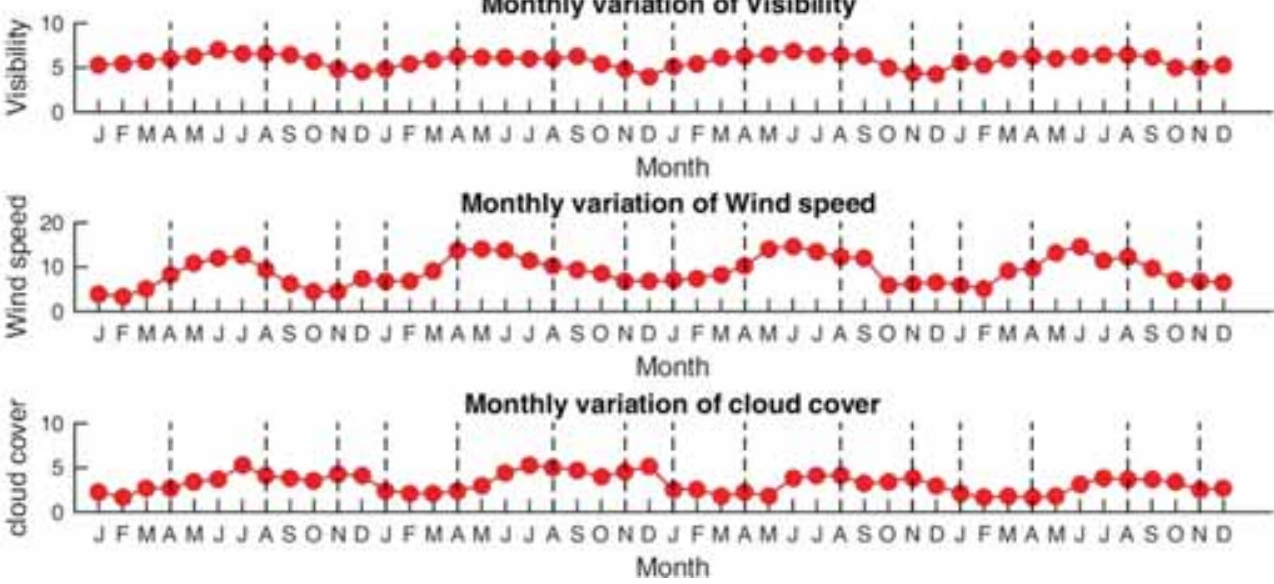

Figure 6. Monthly variation of meteorological parameters for Chennai city.

(a)

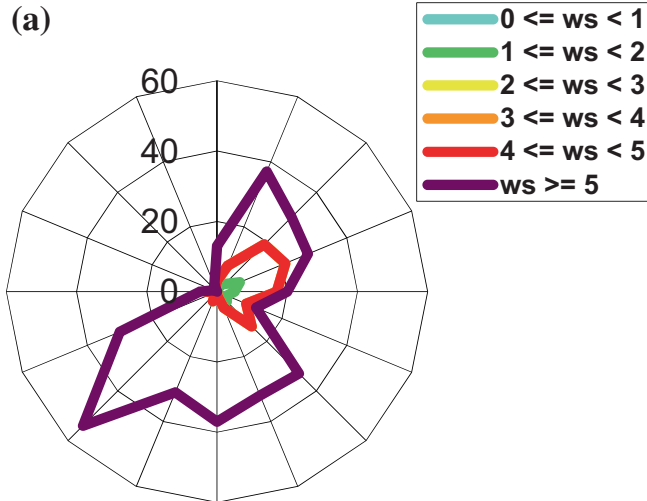

(c)

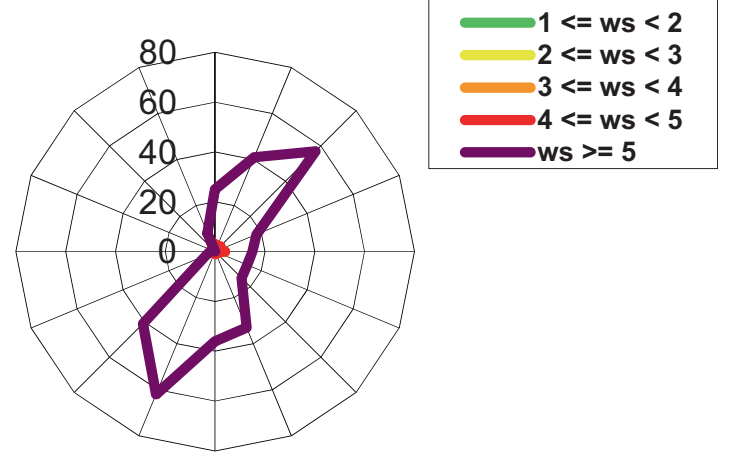

(b)

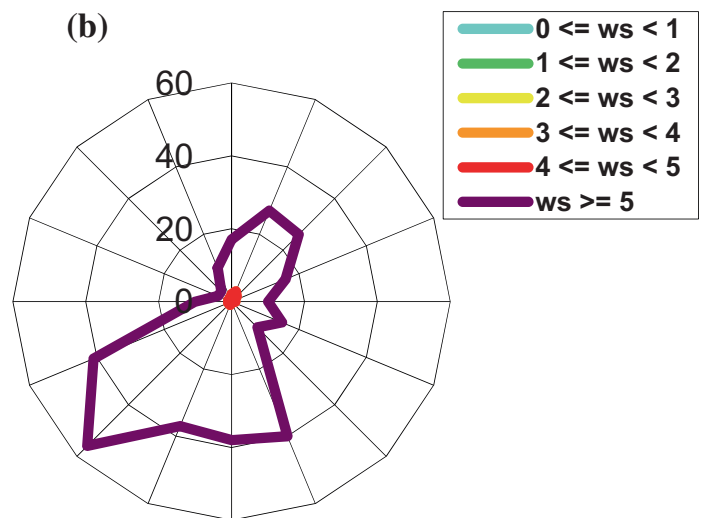

(d)

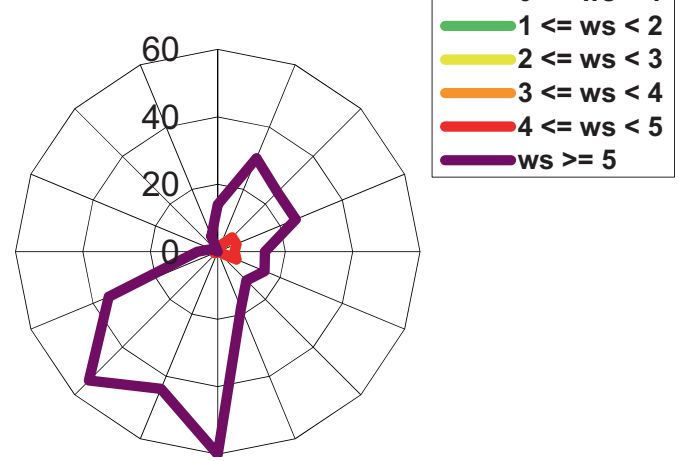

Figure 7. Wind rose plots showing the distribution of wind patterns for Chennai city during the year (a) 2009, (b) 2010, (c) 2011 and (d) 2012 . 
observed in $\mathrm{PM}_{10}$ concentration with higher concentration during the winter season. Monitoring locations in Mumbai showed similar variation in terms of season and meteorology.

\subsection{Statistical distribution of air quality data}

Determination of statistical distribution of air quality data (pollutant concentration) plays an important role in the calculation of exceedances over NAAQS as well the environmental impact of air pollution (Jakeman et al. 1988; Chelani et al. 2002; Jayamurugan et al. 2013). The $Q-Q$ plot was used to identify the statistical distribution of the dataset of the daily average concentration of $\mathrm{SO}_{2}$, $\mathrm{NO}_{2}$ and $\mathrm{PM}_{10}$. The quantile method compares the probability of the values in a dataset with an emperical data distribution created using parameters extracted from the dataset. Figure 5 shows the results of $Q-Q$ plot evaluation for $\mathrm{SO}_{2}, \mathrm{NO}_{2}$ and $\mathrm{PM}_{10}$ at the TS. The results for the rest of the four locations are shown in the supplementary section (figures S6-S9). The best fit was obtained for Weibull distribution in the case of $\mathrm{SO}_{2}$ and $\mathrm{NO}_{2}$ concentrations with exponential showing overprediction at higher quantiles and generalised Pareto showing underprediction at the higher end quantiles. $\mathrm{PM}_{10}$ showed the best fitting with Weibull distribution at Taramani (RS) as compared to other statistical distributions and lognormal for other locations. As shown in tables S9 and S10 in the supplementary section, the Anderson-Darling test and Kolmogorov-Smirnov test showed the best fitting probability distribution as Weibull for daily average $\mathrm{SO}_{2}$ and $\mathrm{NO}_{2}$ concentrations, whereas in the case of $\mathrm{PM}_{10}$ concentration, the lognormal distribution best represents the data, which have been reaffirmed from the literature (Chelani et al. 2002; Lu 2002) (figure 5).

\subsection{Meteorological variation}

Monthly average data were calculated for all the available meteorological parameters (ambient temperature, humidity, wind speed, visibility and cloud cover) (figure 6).

A subtropical and humid climate of Chennai shows high ambient temperature and humidity. The highest monthly average ambient temperature was recorded in the summer months of May and June for all the $4 \mathrm{yr}$ with 2012 being the hottest with an ambient temperature of $35^{\circ} \mathrm{C}$. The least temperature was recorded in the month of January for all the years at a monthly average temperature of $25^{\circ} \mathrm{C}$. The overall monthly average temperature ranges from $25^{\circ} \mathrm{C}$ to $35^{\circ} \mathrm{C}$ over the years. In the case of humidity, the highest values were recorded in the monsoon months of November and December followed by the pre-monsoon period of September and October. The highest wind speed was recorded in the month of June-August.

Peak level in humidity (80-90\%) was recorded during the months of November and December during the south-west monsoon. A dip in the humidity $(60 \%)$ was observed during the summer month of May-July for all the years. The highest wind speed
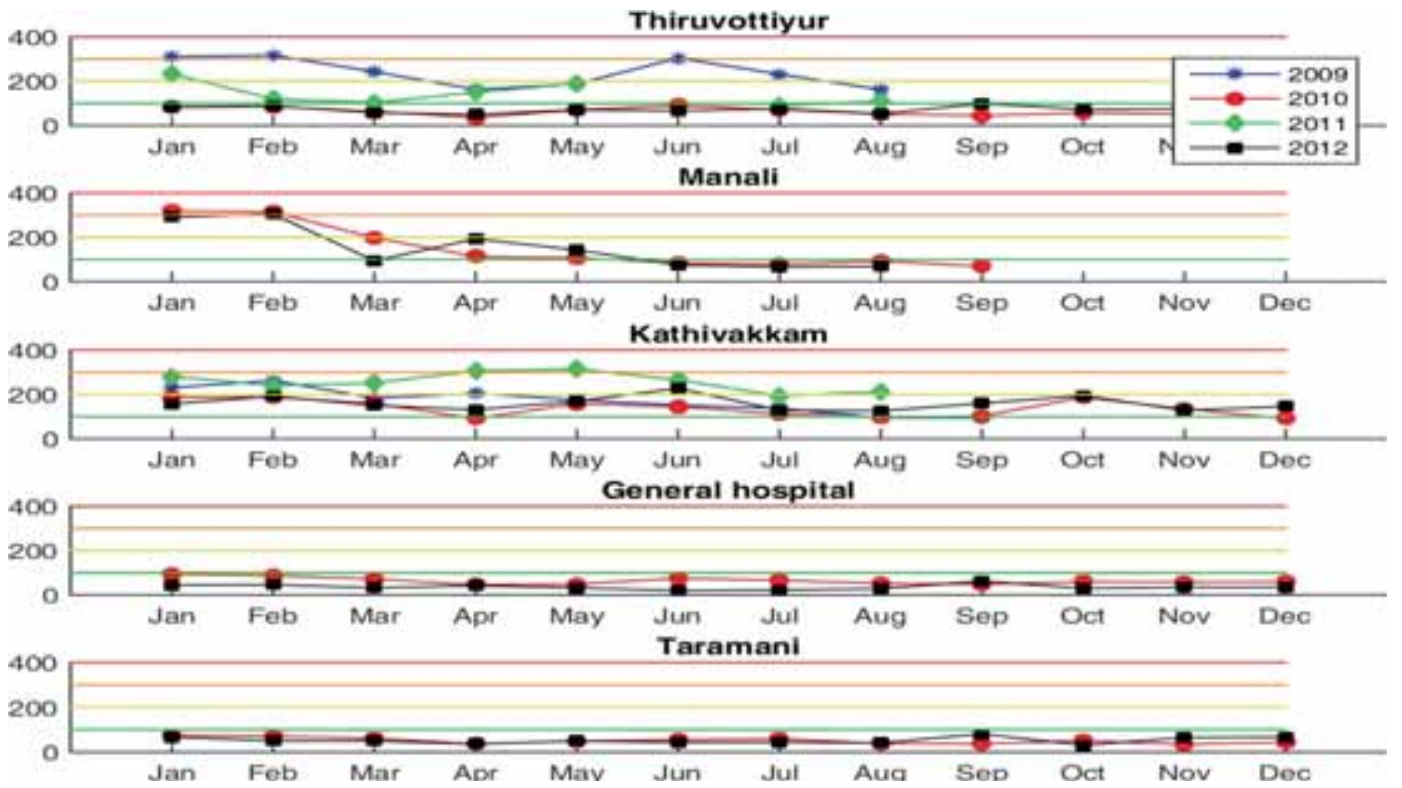

Figure 8. Monthly variation of NAQI for the five monitoring locations in Chennai city during the study period. 
Table 3. Correlation of daily average pollutant concentration with meteorological parameters for different seasons.

\begin{tabular}{|c|c|c|c|c|c|c|c|c|c|c|c|c|}
\hline \multirow{3}{*}{\begin{tabular}{|l} 
Location \\
\\
General hospital \\
\end{tabular}} & \multirow{3}{*}{$\begin{array}{l}\text { Pollutant } \\
\\
\mathrm{SO}_{2} \\
\end{array}$} & \multirow{3}{*}{\begin{tabular}{|l|} 
Season \\
Winter \\
\end{tabular}} & \multicolumn{2}{|c|}{ Temperature } & \multicolumn{2}{|c|}{ Humidity } & \multicolumn{2}{|c|}{ Visibility } & \multicolumn{2}{|c|}{ Wind Speed } & \multicolumn{2}{|c|}{ Cloud Cover } \\
\hline & & & \multirow{2}{*}{$\frac{\text { rho }}{-0.45}$} & \multirow{2}{*}{$p$} & \multirow[b]{2}{*}{0.25} & \multirow[b]{2}{*}{0.51} & \multirow[b]{2}{*}{-0.18} & \multirow[b]{2}{*}{0.65} & \multirow[b]{2}{*}{-0.14} & \multirow[b]{2}{*}{0.73} & \multirow[b]{2}{*}{-0.1} & \multirow[b]{2}{*}{0.8} \\
\hline & & & & & & & & & & & & \\
\hline & & Summer & 0.35 & 0.23 & -0.57 & 0.04 & 0.18 & 0.56 & 0.29 & 0.34 & 0.63 & 0.08 \\
\hline & & Pre-monsoon & 0.16 & 0.54 & -0.04 & 0.87 & 0.22 & 0.42 & 0.17 & 0.53 & -0.17 & 0.52 \\
\hline & & Monsoon & 0.57 & 0.06 & 0.02 & 0.94 & 0.16 & 0.58 & -0.51 & 0.06 & 0.2 & 0.99 \\
\hline & $\mathrm{NO}_{2}$ & Winter & 0.1 & 0.81 & 0.7 & 0.04 & -0.44 & 0.23 & 0.35 & 0.36 & 0.75 & 0.07 \\
\hline & & Summer & -0.32 & 0.29 & 0.29 & 0.33 & -0.18 & 0.55 & -0.35 & 0.24 & -0.27 & 0.38 \\
\hline & & Pre-monsoon & 0.27 & 0.32 & -0.04 & 0.88 & 0.24 & 0.37 & 0.13 & 0.64 & -0.52 & 0.04 \\
\hline & & Monsoon & 0.72 & 0.1 & -0.16 & 0.57 & 0.47 & 0.09 & -0.02 & 0.95 & 0.16 & 0.58 \\
\hline & $\mathrm{PM}_{10}$ & Winter & -0.21 & 0.6 & 0.33 & 0.39 & -0.33 & 0.39 & 0.25 & 0.51 & 0.25 & 0.51 \\
\hline & & Summer & -0.55 & 0.05 & 0.51 & 0.08 & -0.26 & 0.4 & -0.51 & 0.08 & -0.37 & 0.21 \\
\hline & & Pre-monsoon & -0.28 & 0.29 & 0.32 & 0.23 & -0.28 & 0.29 & -0.36 & 0.16 & 0.07 & 0.79 \\
\hline & & \begin{tabular}{|l} 
Monsoon \\
\end{tabular} & 0.58 & 0.08 & 0.05 & 0.86 & 0.33 & 0.24 & -0.27 & 0.35 & 0.1 & 0.74 \\
\hline \multirow[t]{12}{*}{ Kathivakkam } & $\mathrm{SO}_{2}$ & Winter & 0.13 & 0.73 & 0.32 & 0.39 & -0.32 & 0.41 & -0.12 & 0.76 & 0.14 & 0.71 \\
\hline & & Summer & 0.42 & 0.16 & -0.66 & 0.01 & 0.34 & 0.26 & 0.33 & 0.27 & 0.43 & 0.14 \\
\hline & & \begin{tabular}{|l} 
Pre-monsoon \\
\end{tabular} & 0.23 & 0.4 & -0.18 & 0.5 & -0.26 & 0.34 & 0.22 & 0.41 & -0.06 & 0.82 \\
\hline & & Monsoon & 0.48 & 0.08 & -0.53 & 0.05 & 0.56 & 0.04 & 0.27 & 0.35 & -0.33 & 0.24 \\
\hline & $\mathrm{NO}_{2}$ & Winter & -0.14 & 0.72 & 0.65 & 0.06 & -0.71 & 0.03 & -0.34 & 0.38 & 0.45 & 0.22 \\
\hline & & Summer & -0.08 & 0.79 & 0.15 & 0.62 & 0.17 & 0.58 & 0.06 & 0.84 & -0.13 & 0.66 \\
\hline & & Pre-monsoon & -0.3 & 0.26 & 0.22 & 0.42 & -0.2 & 0.46 & -0.04 & 0.87 & 0.31 & 0.24 \\
\hline & & Monsoon & 0.43 & 0.13 & -0.29 & 0.31 & 0.23 & 0.42 & -0.22 & 0.46 & -0.2 & 0.49 \\
\hline & $\mathrm{PM}_{10}$ & Winter & -0.25 & 0.52 & -0.67 & 0.05 & 0.45 & 0.22 & -0.42 & 0.26 & -0.93 & 0 \\
\hline & & Summer & 0.58 & 0.04 & -0.5 & 0.08 & 0.36 & 0.22 & 0.61 & 0.03 & 0.22 & 0.47 \\
\hline & & Pre-monsoon & 0.8 & 0 & -0.67 & 0 & 0.62 & 0.01 & 0.67 & 0 & -0.13 & 0.64 \\
\hline & & \begin{tabular}{|l|} 
Monsoon \\
\end{tabular} & 0.72 & 0 & -0.42 & 0.14 & 0.64 & 0.01 & -0.14 & 0.63 & -0.35 & 0.22 \\
\hline \multirow[t]{9}{*}{ Manali } & $\mathrm{SO}_{2}$ & Winter & 0.12 & 0.75 & -0.59 & 0.1 & 0.36 & 0.34 & -0.08 & 0.83 & -0.62 & 0.08 \\
\hline & & Summer & -0.67 & 0.01 & 0.32 & 0.28 & -0.76 & 0 & -0.61 & 0.03 & -0.1 & 0.74 \\
\hline & & Pre-monsoon & -0.08 & 0.76 & -0.1 & 0.71 & -0.04 & 0.89 & 0.33 & 0.21 & 0.69 & $\overline{0}$ \\
\hline & $\mathrm{NO}_{2}$ & Winter & -0.32 & & 0.66 & & -0.52 & & 0.19 & & 0.74 & \\
\hline & & Summer & -0.62 & 0.4 & 0.28 & 0.05 & -0.29 & 0.15 & -0.48 & 0.63 & -0.06 & 0.02 \\
\hline & & Pre-monsoon & 0.05 & 0.03 & -0.28 & 0.35 & 0.06 & 0.34 & 0.43 & 0.09 & 0.67 & 0.84 \\
\hline & $\mathrm{PM}_{10}$ & Winter & -0.61 & 0.84 & -0.44 & 0.29 & 0.17 & 0.83 & -0.44 & 0.09 & -0.7 & 0 \\
\hline & & Summer & -0.69 & & 0.6 & & -0.65 & & -0.7 & & -0.37 & \\
\hline & & Pre-monsoon & 0.56 & 0.08 & -0.67 & 0.24 & 0.47 & 0.66 & 0.73 & 0.24 & 0.42 & 0.04 \\
\hline \multirow[t]{4}{*}{ Thiruvottiyur } & $\mathrm{SO}_{2}$ & Winter & -0.23 & 0.01 & 0.47 & 0.03 & -0.22 & 0.02 & -0.01 & 0.01 & 0.41 & 0.21 \\
\hline & & Summer & -0.56 & 0.02 & 0.31 & 0 & -0.75 & 0.07 & -0.51 & 0 & -0.29 & 0.1 \\
\hline & & Pre-monsoon & 0.09 & & -0.25 & & 0.29 & & -0.02 & & 0.2 & \\
\hline & & Monsoon & 0.57 & 0.55 & -0.06 & 0.21 & 0.33 & 0.57 & -0.11 & 0.99 & 0.14 & 0.27 \\
\hline
\end{tabular}


Table 3. (Continued.)

\begin{tabular}{|c|c|c|c|c|c|c|c|c|c|c|c|c|}
\hline Location & Pollutant & Season & \multicolumn{2}{|c|}{ Temperature } & \multicolumn{2}{|c|}{ Humidity } & \multicolumn{2}{|c|}{ Visibility } & \multicolumn{2}{|c|}{ Wind Speed } & \multicolumn{2}{|c|}{ Cloud Cover } \\
\hline & $\mathrm{NO}_{2}$ & Winter & -0.19 & 0.05 & 0.32 & 0.31 & -0.26 & 0 & 0.1 & 0.08 & 0.25 & 0.33 \\
\hline & & Summer & 0.09 & 0.75 & 0.02 & 0.36 & 0 & 0.28 & 0.04 & 0.94 & 0.2 & 0.46 \\
\hline & & Pre-monsoon & 0.23 & 0.03 & -0.06 & 0.83 & 0.24 & 0.24 & 0.03 & 0.7 & -0.36 & 0.62 \\
\hline & & Monsoon & 0.74 & 0.62 & -0.31 & 0.4 & 0.58 & 0.51 & -0.04 & 0.79 & -0.12 & 0.51 \\
\hline & $\mathrm{PM}_{10}$ & Winter & -0.64 & 0.78 & -0.04 & 0.95 & -0.09 & 0.99 & -0.24 & 0.89 & -0.2 & 0.51 \\
\hline & & Summer & -0.12 & 0.39 & 0.02 & 0.82 & -0.23 & 0.37 & -0.19 & 0.91 & 0.08 & 0.17 \\
\hline & & Pre-monsoon & -0.18 & 0 & 0.27 & 0.28 & -0.32 & 0.03 & -0.17 & 0.9 & -0.25 & 0.67 \\
\hline & & Monsoon & 0.52 & 0.06 & 0.07 & 0.92 & 0.22 & 0.82 & -0.3 & 0.53 & 0.11 & 0.6 \\
\hline Taramani & $\mathrm{SO}_{2}$ & Winter & -0.43 & 0.7 & 0.1 & 0.96 & -0.17 & 0.45 & 0.16 & 0.54 & 0.03 & 0.8 \\
\hline & & Summer & -0.21 & 0.51 & 0.08 & 0.31 & -0.14 & 0.22 & 0.03 & 0.52 & 0.37 & 0.35 \\
\hline & & Pre-monsoon & 0.19 & 0.06 & -0.32 & 0.82 & 0.06 & 0.45 & 0.41 & 0.29 & 0.16 & 0.72 \\
\hline & & Monsoon & 0.65 & 0.25 & -0.16 & 0.8 & 0.36 & 0.67 & -0.06 & 0.68 & 0.18 & 0.95 \\
\hline & $\mathrm{NO}_{2}$ & Winter & -0.14 & 0.5 & -0.28 & 0.79 & 0.05 & 0.65 & -0.27 & 0.92 & -0.5 & 0.22 \\
\hline & & Summer & 0.5 & 0.48 & -0.69 & 0.23 & 0.23 & 0.84 & 0.58 & 0.12 & 0.29 & 0.56 \\
\hline & & Pre-monsoon & 0.54 & 0.01 & -0.62 & 0.59 & 0.42 & 0.21 & 0.68 & 0.83 & 0.03 & 0.54 \\
\hline & & Monsoon & 0.62 & 0.71 & -0.22 & 0.47 & 0.46 & 0.89 & -0.03 & 0.48 & 0.04 & 0.17 \\
\hline & $\mathrm{PM}_{10}$ & Winter & -0.69 & 0.08 & -0.05 & 0.01 & -0.32 & 0.46 & -0.27 & 0.04 & -0.28 & 0.33 \\
\hline & & Summer & 0.66 & 0.03 & -0.76 & 0.01 & 0.34 & 0.1 & 0.61 & 0 & 0.39 & 0.92 \\
\hline & & Pre-monsoon & 0.86 & 0.02 & -0.73 & 0.46 & 0.54 & 0.1 & 0.71 & 0.92 & -0.16 & 0.89 \\
\hline & & Monsoon & 0.86 & 0.04 & -0.73 & 0.91 & 0.54 & 0.39 & 0.71 & 0.48 & -0.16 & 0.46 \\
\hline
\end{tabular}

was observed during the summer season at 12-15 $\mathrm{km} / \mathrm{h}$. High wind speed occurred due to the formation of a low-pressure regions caused by the heating of ambient air during the summer season. The least wind speed was recorded during the months of January and February in the range of 4-7 km/h. Visibility of up to $7 \mathrm{~km}$ was observed during the summer months between May and July with a decrease during the winter and south-west monsoon. The lowest visibility value of $4 \mathrm{~km}$ was observed during the monsoon.

Figure 7 shows the distribution of wind direction and wind speed for the year 2009-2012. The categories of the wind speed were designated as follows: $337.5^{\circ}<\mathrm{N} \leq 22.5^{\circ}, 22.5^{\circ}<\mathrm{NE} \leq 67.5^{\circ}$, $67.5^{\circ}<\mathrm{E} \leq 112.5^{\circ}, 112.5^{\circ}<\mathrm{SE} \leq 157.5^{\circ}$, $157.5^{\circ}<\mathrm{S} \leq 202.5^{\circ}, 202.5^{\circ}<\mathrm{SW} \leq 247.5^{\circ}$, $247.5^{\circ}<\mathrm{W} \leq 292.5^{\circ}$ and $292.5^{\circ}<\mathrm{NW} \leq 337.5^{\circ}$. The predominant wind direction was found to be south-west and south-south-west during the years. Wind speed was mostly in the category $\geq 5 \mathrm{~m} / \mathrm{s}$. In 2009, most wind speed observations were in $\geq 5 \mathrm{~m} / \mathrm{s}$ wind velocity class and only a few observations were in $4-5$ and $1-2 \mathrm{~m} / \mathrm{s}$ class. The most wind observations were recorded in the southwest direction followed by north-north-east. During the study period, most observations were found in $\geq 5 \mathrm{~m} / \mathrm{s}$ wind speed category in the south-west direction followed by a south direction.

\subsection{Correlation analysis}

Correlation between pollutant concentration and meteorological parameters was calculated for all the seasons and all the locations. Table 2 shows the PMCC of weekly pollutant concentration with five meteorological parameters such as temperature, humidity, visibility, wind speed and cloud cover. The correlation plots for the monitoring locations are added in the supplementary figures S1-S5. The rows of subplots in the figure signify the season for which the data were collected. In the case of General Hospital, high correlation was observed for $\mathrm{SO}_{2}$ with ambient temperature for monsoon season at $(R=0.57) p=0.06$ and with cloud cover for summer season at $(R=0.63)$ 
$p=0.08$. All the other meteorological parameters had a low or negative correlation. In the case of $\mathrm{NO}_{2}$, higher correlation was observed in the case of temperature for monsoon at $(R=0.72)$ $p=0.1$ and cloud cover for winter at $(R=$ 0.75) $p=0.07$. All the other correlation values were either low or negative. In the case of $\mathrm{PM}_{10}$, higher correlation was observed in the case of temperature for monsoon at $(R=0.58) p=0.08$ and humidity for summer season $(R=0.51)$ at $p=0.08$. All the other correlation values were either low or negative. In the case of Kathivakkam, for $\mathrm{NO}_{2}$ concentration, the high positive correlation was observed with temperature during the monsoon and with humidity and cloud cover during the winter season. As detailed in table 2, all the pollutant observations showed highly positive to low negative correlation except in the case of winter season where the correlation in highly negative due to the lower mixing height and stable atmospheric conditions. Humidity showed mostly a negative or weak positive correlation. The weak positive correlation can be attributed to the partition of semi-volatile species into the aerosol phase, whereas the negative correlation is due to the deposition and dissolution of pollutants especially during the monsoon and pre-monsoon periods. All the pollutants showed mostly the negative correlation with wind speed, which is due to the horizontal dispersion caused by the increase in wind speed.

\subsection{NAQI evaluation}

Monthly average concentration of $\mathrm{SO}_{2}, \mathrm{NO}_{2}$ and $\mathrm{PM}_{10}$ was used for evaluation of NAQI for the monitoring locations over the study duration. Figure 8 shows the monthly NAQI values calculated for each location. Line plots in each subplot signify the years for which the data were available. Horizontal lines denote the class interval for each air quality category. As shown in the subplots NAQI showed higher values for the winter months of January and February for all industrial locations. The higher AQI leading to health problems can be attributed to lower mixing height causing stable meteorological conditions as well as emissions from petrochemical industries and thermal power plant in the industrial areas of northern Chennai. NAQI values were healthy for Taramani and General Hospital as no exceedances were observed for $\mathrm{PM}_{10}$ in the locations. It can be concluded from the observation of ambient concentration time series and NAQI plots that $\mathrm{PM}_{10}$ was the responsible pollutant for higher AQI as the other two criteria pollutants were $\left(\mathrm{NO}_{2}\right.$ and $\mathrm{SO}_{2}$ ) always well below the NAAQS.

\section{Conclusion}

Daily average pollutant concentration from five monitoring locations in Chennai city over $4 \mathrm{yr}$ (2009-2012) was analysed. The following observations were made from the data analysis (table 3 ):

- Monthly and seasonal trends showed a higher concentration during the winter season and a decrease in concentration during the monsoon. Pollutant concentration (especially $\mathrm{PM}_{10}$ ) was distinctively higher at the industrial monitoring locations.

- An increasing trend was observed from 2009 to 2012 for all pollutants attributed to the vehicle and industrial emissions.

- Analysis of meteorological parameters showed an increase of temperature and wind speed over the years with the summer season showing the peak values for every year. The highest level of monthly humidity was observed during the monsoon of 2010. Wind rose plots showed a predominant wind direction in the south and south-west directions and the majority of wind speed data falls in the $\geq 5 \mathrm{~m} / \mathrm{s}$ category.

- Correlation plots of pollutant concentration (especially in the case of $\mathrm{PM}_{10}$ ) with meteorological parameters showed a higher positive correlation $(R>0.5)$ with temperature and humidity as compared to other meteorological parameters.

- Statistical distribution of daily average air quality parameters was also analysed using nonparametric hypothesis tests (Anderson-Darling test and Kolmogorov-Smirnov test) and graphical technique called $Q-Q$ plot. The plots showed that the concentration of $\mathrm{SO}_{2}$ and $\mathrm{NO}_{2}$ mostly showed Weibull distribution, whereas $\mathrm{PM}_{10}$ followed Weibull distribution at Taramani and lognormal distribution at all the other locations.

- NAQI showed the worst air quality during the winter season. Air quality was good at Taramani (residential site) and General Hospital (TS). In the case of industrial locations, air quality ranged between moderately polluted to very poor during the winter season. 
The results of the above study can be used for forecasting air quality in Chennai city using the air quality parameters and meteorology. It will also help policymakers in applying effective measures to mitigate air pollution in sub-humid tropical regions.

\section{Acknowledgements}

We would like to acknowledge the Tamil Nadu Pollution Control Board for providing daily average air quality data through their website. Meteorological data were obtained from the Weather Underground and air quality data for Mumbai city were downloaded from the Data.gov.in website. We are thankful to the above organisations for making the data available through their websites.

\section{References}

Baldasano J M, Valera E and Jiménez P 2003 Air quality data from large cities; Sci. Total Environ. 307 141-165, https://doi.org/10.1016/S0048-9697(02)00537-5.

Banerjee T, Singh S B and Srivastava R K 2011 Development and performance evaluation of statistical models correlating air pollutants and meteorological variables at Pantnagar, India; Atmos. Res. 99 505-517, https://doi. org/10.1016/j.atmosres.2010.12.003.

Bell M C, Galatioto F, Chakravartty A and Namdeo A 2013 A novel approach for investigating the trends in nitrogen dioxide levels in UK cities; Environ. Pollut. 183 184-194, https://doi.org/10.1016/j.envpol.2013.03.039.

Berger A, Melice J L and Demuth C 1982 Statistical distributions of daily and high atmospheric SO2-concentrations; Atmos. Environ. 16 2863-2877.

Chelani A B, Rao C V C, Phadke K M and Hasan M Z 2002 Formation of an air quality index in India; Int. J. Environ. Stud. 59 331-342, https://doi.org/10.1080/ 00207230211300.

CPCB 2011 Guidelines for manual sampling 8 analyses; Central Pollution Control Board (Ministry of Environment and Forests, Govt. of India).

Frank L, Sallis J, Conway T, Chapman J, Saelens B and Bachman W 2006 Many pathways from land use to health and air quality; J. Am. Plan. Assoc. 72 75-87, https:// doi.org/10.1080/01944360608976725.

Gokhale S and Khare M 2007 A theoretical framework for the episodic-urban air quality management plan (e-UAQMP); Atmos. Environ. 41 7887-7894, https://doi.org/10.1016/ j.atmosenv.2007.06.061.

Govt. of India 2018 https://data.gov.in/catalog/historicaldaily-ambient-air-quality-data; Open Govt. data (OGD) platform India.

Gurjar B R, Butler T M, Lawrence M G and Lelieveld J 2008 Evaluation of emissions and air quality in megacities; Atmos. Environ. 42 1593-1606, https://doi.org/10.1016/ j.atmosenv.2007.10.048.
Hargreaves P R, Leidi A, Grubb H J, Howe M T and Mugglestone M A 2000 Local and seasonal variations in atmospheric nitrogen dioxide levels at Rothamsted, UK, and relationships with meteorological conditions; Atmos. Environ. 34 843-853, https://doi.org/10.1016/ S1352-2310(99)00360-X.

Hoek G, Beelen R, De Hoogh K, Vienneau D, Gulliver J, Fischer P and Briggs D 2008 A review of land-use regression models to assess spatial variation of outdoor air pollution; Atmos. Environ. 42 7561-7578, https://doi.org/10.1016/ j.atmosenv.2008.05.057.

Holland M and Fitz-simons T 1981 Fitting statistical distributions to air quality data by the maximum likelihood method; Atmos. Environ. 17 1071-1077.

Huang J, Zhou C, Lee X, Bao Y, Zhao X, Fung J, Richter A, Liu X and Zheng Y 2013 The effects of rapid urbanisation on the levels in tropospheric nitrogen dioxide and ozone over East China; Atmos. Environ. 77 558-567, https:// doi.org/10.1016/j.atmosenv.2013.05.030.

Jakeman A J 1986 Modelling distributions of air pollutant concentrations-II estimation of one and two parameter statistical distributions; Atmos. Environ. 20 2435-2447.

Jakeman A J, Simpson R W and Taylor J A 1988 Modelling distributions of air pollutant concentrations-III. The hybrid deterministic-statistical distribution approach; Atmos. Environ. 22 163-174.

Jayamurugan R, Kumaravel B, Palanivelraja S and Chockalingam M P 2013 Influence of temperature, relative humidity and seasonal variability on Ambient Air Quality in a Coastal Urban Area; Int. J. Atmos. Sci. 2013 1-7, https://doi.org/10.1155/2013/264046.

Kampa M and Castanas E 2008 Human health effects of air pollution; Environ. Pollut. 151 362-367, https://doi.org/ 10.1016/j.envpol.2007.06.012.

Kamyotra J S and Basu D D 2011 National ambient air quality status; $162 \mathrm{p}$.

Kanchan K, Gorai A K and Goyal P 2015 A review on air quality indexing system; Asian J. Atmos. Environ. 9 101113, https://doi.org/10.5572/ajae.2015.9.2.101.

Krishnamurthy R and Desouza K C 2015 Chennai, India; Cities 42 118-129, https://doi.org/10.1016/j.cities.2014. 09.004 .

Lu H C 2002 The statistical characters of PM10 concentration in Taiwan area; Atmos. Environ. 36 491-502, https://doi.org/10.1016/S1352-2310(01)00245-X.

Mage D, Webster A and Peterson P 1996 Urban air pollution in megacities of the world; Atmos. Environ. 30 681-686.

Masiol M and Harrison R M 2015 Quantification of air quality impacts of London Heathrow Airport (UK) from 2005 to 2012; Atmos. Environ. 116 308-319, https://doi.org/ 10.1016/j.atmosenv.2015.06.048.

Mayer H 1999 Air pollution in cities; Atmos. Environ. 33 4029-4037, https://doi.org/10.1016/S1352-2310(99) 00144-2.

Monn C 2001 Exposure assessment of air pollutants: A review on spatial heterogeneity and indoor/outdoor/ personal exposure to suspended particulate matter, nitrogen dioxide and ozone; Atmos. Environ. 35 1-32, https://doi.org/10.1016/S1352-2310(00)00330-7. 
Nadel J A, Salem H, Tamplin B and Tokiwa Y 1965 Mechanism of bronchoconstriction during inhalation of sulphur dioxide; J. Appl. Physiol. 20 164-167.

Plaia A and Ruggieri M 2010 Air quality indices: A review; Rev. Environ. Sci. Bio/Technol. 10 165-179, https://doi. org/10.1007/s11157-010-9227-2.

Shooter D and Brimblecombe P 2005 Air quality indexing; Int. J. Environ. Pollut. 36(1-3) 1-24.

Stigler S M 1989 Francis Galton's account of the invention of correlation; Stat. Sci. 4 73-79.

Taylor J A, Jakeman A J and Simpson R W 1986 Modelling distributions of air pollutant concentrations-I. Identification of statistical models; Atmos. Environ. 20 1781-1789.

Corresponding editor: Amit Kumar PATRA
Tecer L H and Tagil S 2013 Spatial-temporal variations of sulphur dioxide concentration, source, and probability assessment using a GIS-based geostatistical approach; Pol. J. Environ. Stud. 22 1491-1498.

Weather Underground 2018 https://www.wunderground. com/weather/in/chennai-airport; The Weather Channel Product and technology LLC 2014, 2018.

Zvyagintev A M, Kuznetsova I N, Tarasova O A and Shalygina I Y 2014 Variations in the concentrations of main air pollutants in London; Atmos. Radiat., Opt. Weather, Clim. 27 417-427, https://doi.org/10.1134/ S1024856014050170. 